\title{
The Real-World status and risk factors for a poor prognosis in elderly patients with primary central nervous system malignant lymphomas: a multicenter retrospective cohort study of the Tohoku Brain Tumor Study Group
}

Kenichiro Asano ( $\square$ asanoken@hirosaki-u.ac.jp )

Hirosaki Daigaku Igakubu Daigakuin Igaku Kenkyuka https://orcid.org/0000-0002-4147-4312

Yoji Yamashita

Miyagi Cancer Center: Miyagi Kenritsu Gan Center

Takahiro Ono

Akita University: Akita Daigaku

Manabu Natsumeda

Niigata University: Niigata Daigaku

Takaaki Beppu

Iwate Medical University: Iwate Ika Daigaku

Kenichiro Matsuda

Yamagata University: Yamagata Daigaku

Masahiro Ichikawa

Fukushima Kenritsu Ika Daigaku

Masayuki Kanamori

Tohoku University: Tohoku Daigaku

Masashi Matsuzaka

Hirosaki University School of Medicine Graduate School of Medicine: Hirosaki Daigaku Igakubu

Daigakuin Igaku Kenkyuka

\section{Akira Kurose}

Hirosaki University School of Medicine Graduate School of Medicine: Hirosaki Daigaku Igakubu

Daigakuin Igaku Kenkyuka

Kiyoshi Saito

Fukushima Kenritsu Ika Daigaku

Yukihiko Sonoda

Yamagata University: Yamagata Daigaku

Kuniaki Ogasawara

Iwate Medical University: Iwate Ika Daigaku 


\section{Yukihiko Fujii}

Niigata University: Niigata Daigaku

\section{Hiroaki Shimizu}

Akita University: Akita Daigaku

\section{Hiroki Ohkuma}

Hirosaki University School of Medicine Graduate School of Medicine: Hirosaki Daigaku Igakubu Daigakuin Igaku Kenkyuka

\section{Chifumi Kitanaka}

Yamagata University Faculty of Medicine Graduate School of Medical Science: Yamagata Daigaku Igakubu Daigakuin Igakukei Kenkyuka

\section{Takamasa Kayama}

Yamagata University Faculty of Medicine Graduate School of Medical Science: Yamagata Daigaku Igakubu Daigakuin Igakukei Kenkyuka

\section{Teiji Tominaga}

Tohoku University: Tohoku Daigaku

\section{Research Article}

Keywords: elderly patient, PCNSL, risk factor

Posted Date: March 10th, 2021

DOl: https://doi.org/10.21203/rs.3.rs-291646/v1

License: (c) (i) This work is licensed under a Creative Commons Attribution 4.0 International License. Read Full License

Version of Record: A version of this preprint was published at International Journal of Clinical Oncology on October 12th, 2021. See the published version at https://doi.org/10.1007/s10147-021-02042-3. 


\section{Abstract}

\section{Introduction}

The number of elderly patients with primary central nervous system malignant lymphoma(EL-PCNSL) has been increasing. However, due to their poor pre-treatment Karnofsky Performance Status(KPS) and many comorbidities, it is possible that sufficient treatment has not been performed. We therefore conducted a retrospective cohort study to evaluate risk factors associated with a poor prognosis of the Real-World status of EL-PCNSL in the Tohoku Brain Tumor Study Group.

\section{Methods}

Patients aged $\geq 71$ years with PCNSL were enrolled from 8 centers. Univariate analysis was performed by the log-rank test. A Cox proportional hazards model was used for multivariate analysis.

\section{Results}

Three of total 142 cases received best supportive care(BSC) from the beginning. Treatment was given to 30 cases without a pathological diagnosis, 3 cases with a cerebrospinal fluid diagnosis, and 100 cases with CD20-positive DLBCL diagnosis. Total 133 cases(median age 76 years) were included. The median pre-treatment KPS was $50 \%$. There were $117(88.0 \%)$ patients with 213 pre-treatment comorbidities(1.8 comorbidities per patient). PFS and OS were 16 months and 24 months, respectively. Risk factors associated with poor prognosis on Cox proportional hazards model were pre-treatment cardiovascular disease and central nervous system disease comorbidities, post-treatment pneumonia and other infections, and the absence of radiation or chemotherapy.

\section{Conclusions}

EL-PCNSL was actively treated and BSC was only a few. Pre-treatment comorbidities and post-treatment complications would influence the prognosis. Radiation and chemotherapy were found to be effective, but no conclusions could be drawn regarding the content of chemotherapy and whether additional radiation therapy should be used.

\section{Introduction}

Primary central nervous system malignant lymphoma (PCNSL) is considered to be a common disease in the elderly, with more than half of patients over 60 years of age[1], and the ratio of PCNSL among all brain tumors has been increasing in recent years. In the Report of the Brain Tumor Registry of Japan, the percentage of all-age PCNSLs among all brain tumors increased from 3.1\% from 1984 to 2000 to $4.5 \%$ from 2005 to 2008. The proportion of PCNSL occurring in patients aged 70 years or older (elderly patients 
with PCNSL(EL-PCNSL)) has also increased, from $28.1 \%$ to $35.9 \%[2,3]$. However this applies not only to Japan, but also to other countries[4-6].

The proportion of patients over 70 years of age has been increasing as a result of the aging of the population, but the proportion of EL-PCNSL among all brain tumors has also been increasing, making it more likely to be encountered in daily clinical practice. Patients with EL-PCNSL are expected to have lower pre-treatment Karnofsky Performance Status (KPS) and more pre-treatment comorbidity than younger patients, which may lead to unavoidable best supportive care (BSC), omitted biopsies, and unsatisfactory treatment due to various pre-treatment comorbidities. In addition, patients with EL-PCNSL are rarely included in prospective clinical trials[7, 8] making it difficult to determine the actual exact treatment status $[9,10]$.

Therefore, how many patients are actually diagnosed and treated is not known. To answer this question, the incidence, treatment, and final outcome of PCNSL in elderly patients in the Tohoku and Niigata regions in the Tohoku Brain Tumor Study Group were examined to identify factors associated with a poor prognosis, and the Real-World status of PCNSL in elderly patients was examined.

\section{Materials And Methods}

A Real-World study of all patients with immunocompetent EL-PCNSL aged 71 years or older who were treated or not treated and followed-up with best support care (BSC) at 8 centers participating in the Tohoku Brain Tumor Study Group from January 2011 to the end of December 2018 was performed. Cases diagnosed as PCNSL by imaging alone without biopsy or resection, cases treated based on cerebrospinal fluid (CSF) cytology and imaging, and cases treated based on biopsy or resection were included. Patients who were treated based on imaging findings alone were evaluated by their physicians based on the response rate comparing pre-treatment MRI and post-treatment MRI (at least PR or better response after initial chemotherapy or radiotherapy). Patients who underwent biopsy or resection were diagnosed as having CD-20 positive PCNSL by central pathological diagnosis.

An Excel questionnaire was sent to each institution, and the survey was conducted by linkable anonymizing from each patient's medical record and image server. The survey items included basic patient information, time from initial symptom to diagnosis, pre-treatment KPS, pre-treatment comorbidities, target lesion location, maximum tumor diameter, multiple lesions or no, presence of dissemination on MRI or clinical symptoms, surgery, radiotherapy, dose and technique of radiotherapy, presence of chemotherapy and number of cycles, presence of new post-treatment complications, and best MRI response at the end of treatment (within 3 months). KPS at 3 months, progression-free survival (PFS), treatment at recurrence, overall survival (OS), and cause of death were also investigated.

The start date of treatment was defined as the start date of chemotherapy or radiation therapy (RT). PFS was defined as the date of confirmation of tumor growth or until the date of death. OS was defined as the date of final confirmation of survival or until the date of death. The last follow-up was December 31, 2018. Tumor size was determined using the Macdonald Criteria[11], and the response rate was 
determined according to the International Primary CNS Lymphoma Collaborative Group (IPCNSLCG)[12]. For the determination of the MRI best response rate within 3 months after treatment, RR was defined as $\mathrm{CR}+\mathrm{CRu} / \mathrm{PR}+\mathrm{NC}+\mathrm{PD}+\mathrm{NA}$ (not determined).

In the statistical analysis, age, time to diagnosis, maximum tumor diameter, and pre-treatment and posttreatment KPS were compared between the below/above median groups. For pre-treatment comorbidities and new post-treatment complications, only items with more than 10 comorbidities and complications were subjected to statistical analysis. Univariate analysis was performed by the log-rank test using the Kaplan-Meier method. A Cox proportional hazards model was used for multivariate analysis of risk factors. The entire statistical analysis was performed on a Mac OSX 10.15.7 operating system, using the JMPÒ14(SAS Institute, Cary, NC, USA) statistical software.

\section{Results}

\section{Background characteristics of the cases}

A total of 142 patients were enrolled. Of these, two patients were excluded due to secondary central nervous system lymphoma. There were 3 cases of BSC without aggressive treatment based on imaging diagnosis alone. Thirty-one patients were treated with radiation or chemotherapy without surgery based on imaging diagnosis alone. Of these, 1 case was excluded due to difficulty in MRI follow-up, and only 3 cases were treated as PCNSL due to imaging diagnosis, cytological diagnosis by lumbar puncture, and abnormally high levels of IL-2R in CSF. A total of 103 patients underwent surgical removal or biopsy for tissue confirmation, and they were treated at each institution. These specimens were reviewed, but two cases had very little tumor cell component and could not be diagnosed by central pathological review, and one case had no tumor cell component and could not be diagnosed. All of the 100 cases with tissue confirmation were CD-20 positive diffuse large $B$ cell malignant lymphoma (DLBCL). A total of 133 cases, including 30 cases without tissue confirmation, 3 cases diagnosed by CSF examination, and 100 cases with tissue confirmation, were examined (Fig. 1).

The characteristics of the 133 cases ( 65 males and 68 females; median age 76 years) are shown in Table 1. The pre-treatment KPS ranged from $30 \%$ to $90 \%$ (median $50 \%$ ).

As initial treatment, 110 patients $(82.7 \%)$ received $\mathrm{RT}$, and 97 patients $(72.9 \%)$ received chemotherapy. RT alone was used in 32 patients (24.1\%), with high-dose methotrexate(HD-MTX)+RT in 59 patients (44.4\%), R-MPV(rituximab, MTX, procarbazine, and vincristine) (including MPV or R-MPV-A(rituximab, MTX, procarbazine, vincristine and Ara-C))+RT in 14 patients (10.5\%); chemotherapy alone was used in only 14 patients (10.5\%) and R-MPV (including MPV or R-MPV-A) was used in 5 patients (3.6\%). In addition, 4 patients $(3.0 \%)$ who were dropout cases in the early treatment phase failed to receive treatment in the initial phase (more on this later).

There were 61 cases of relapse during the follow-up period. Of these, 32 (52.5\%) were given BSC as second-line therapy, accounting for about half of the cases. Savage RT was added in 8 cases (13.1\%), 
Salvage RT and chemotherapy were added in 8 cases (13.1\%), and Salvage chemotherapy alone was added in 13 cases (21.3\%). The final outcome at the end of follow-up was survival in 39 patients (29.3\%), death in 76 patients $(57.1 \%)$, and no outcome information was available in 18 patients $(13.5 \%)$.

\section{Treatment and response rate}

The overall median (m)PFS was 16 months $(95 \% \mathrm{Cl}, 12-20)$ and median $(\mathrm{m})$ OS was 24 months $(95 \% \mathrm{Cl}$, 16-30), despite the variety of treatments, radiosurgery, chemotherapy, and number of cycles. In addition, there was a significant difference in mOS between the 32 patients treated with RT alone and the 59 patients treated with HD-MTX+RT (12 months and 32 months, $p<0.001)$. A comparison of 32 patients in the RT alone group and 14 patients in the R-MPV+RT (including MPV or R-MPV-A) group also showed a significant difference $(p=0.036)$, although the R-MPV group had not yet reached mOS. There was no significant difference between the HD-MTX+RT treatment group and the R-MPV+RT (or MPV or R-MPV-A) group ( $p=0.79$ ). $R-M P V$ or $R-M P V$ therapy is a recently introduced therapy with a maximum follow-up of 48 months.

The best response within the first 3 months of treatment was interpreted as CR in 35 (26.3\%), CRu in 52 (39.1\%), PR in 40 (30.1\%), SD in 0 (0.0\%), and PD in $3(2.3 \%)$ cases. Thus, CR+CRu was observed in 87 (65.4\%) cases.(Table 1 and Fig. 2)

\section{Pre-treatment comorbidities}

There were 117 patients (88.0\%) with pre-treatment comorbidities and 16 patients $(12.0 \%)$ with no comorbidities at all. The total number of comorbidities was 213 , or 1.8 comorbidities per patient. The most common pre-treatment comorbidity was hypertension, with 56 cases $(26.3 \%)$. This was followed by central nervous system diseases such as post-stroke syndrome and dementia, with 24 cases $(11.3 \%)$. Cardiovascular diseases such as arrhythmia, heart failure, angina pectoris, and myocardial infarction accounted for 21 cases (9.9\%), comorbidities of systemic cancer other than brain tumor accounted for 20 cases $(9.4 \%)$, and diabetes mellitus accounted for 17 cases (8.0\%).(Table 1$)$

\section{Dropout cases in the early treatment phase and the cause of death}

A total of $15(11.3 \%)$ patients dropped out within 3 months after the start of treatment, including those with complications from surgery, all of which occurred within 2 months. The breakdown was as follows: 4 patients died of complications including operation-related complications $(26.7 \%), 4$ patients died of tumors (26.7\%), 1 patient refused treatment (6.7\%), 6 patients were lost due to hospital transfer $(40.0 \%)$. The breakdown of the 4 deaths due to complications was: 1 patient died of Pneumocystis carinii pneumonia, 1 patient died of pulmonary embolism (PE) due to upper gastrointestinal bleeding and deep venous thrombosis (DVT), 1 patient died of myelosuppression, cholecystitis, and pseudoenteritis, and 1 patient died of postoperative biopsy hemorrhage.

\section{Post-treatment complications and causes of death}


Table 1 shows the post-treatment complications (complications during the course of treatment), including the above early dropout cases. Fifty-four patients $(40.6 \%)$ had some complications during the course of treatment, and 79 patients $(59.4 \%)$ had no complications. The total number of complications was 84 in 54 patients, or a rate of 1.6 per patient. The most common complication was pneumonia and other infections in 28 patients (33.3\%), followed by DVT, PE, and cardiac disease in 12 patients (14.3\%), and renal dysfunction including delayed MTX excretion in 11 patients (13.1\%). There were two cases of postoperative hemorrhage, including the above-mentioned fatal case.

The number of deaths at the last follow-up was 76 (57.1\%), of which 38 (50.0\%) were apparent tumor deaths, 33 (43.4\%) were complication deaths, and 5 (6.6\%) were deaths of unknown cause, accounting for about half of the deaths and about one-quarter of the total population. The breakdown of deaths due to complications was pneumonia and other infections in 15 patients (45.5\%), accounting for about half of the deaths due to complications.

\section{Risk factors associated with a poor prognosis}

\section{Univariate analysis}

Significant differences of mOS were observed in cardiovascular disease (+ 11 months vs. - 27 months, $p=0.001)$, central nervous system disease ( 9 months vs. +26 months, $p=0.038)$, post-treatment KPS ( $<60 \% 12$ months vs. $\geq 60 \% 34$ months, $p<0.001$ ), presence of chemotherapy ( +30 months vs. -12 months, $p<0.001)$, presence of radiotherapy ( +25 months vs. -9 months, $p=0.045)$, best response rate of CR and CRu within 3 months (CR and CRu 30 months vs. PR, SD, PD, and NA 12 months, $p=0.013$ ), posttreatment pneumonia and other infections ( +16 months vs. -27 months, $p<0.001)$, and post-treatment DVT, PE, and cardiac complications (+ 11.5 months vs. -26 months, $p=0.001)$ (Tables 1 and Fig. 3 ).

\section{Cox proportional hazards model}

Independent variables were defined as age ( $\geq 76 /<76$ years), sex $(M / F)$, pre-treatment $\mathrm{KPS}(<50 \% / \geq 50 \%)$, $\mathrm{HT}(+/-), \mathrm{DM}(+/-), \mathrm{HL}(+/-)$, previous systemic cancer (+/-), history of cardiovascular disease (+/-), history of central nervous system disease $(+/-)$, chemotherapy $(-/+)$, radiotherapy $(-/+)$, post-treatment KPS $(<60 /$ $\geq 60$ ), best response rate within 3 months $(C R+C R u / P R+N C+P D+N C)$, post-treatment pneumonia/other infections (+/-), post-treatment DVT/PE/cardiac disease (+/-), and renal dysfunction (+/-); multivariate analysis was performed using a Cox proportional hazards model. The results showed that there was a significant association between pre-treatment cardiovascular disease (HR 3.432; 95\% Cl 1.612-7.065; $\mathrm{p}=0.002$ ), pre-treatment central nervous system disease (HR 2.869; 95\% Cl 1.280-6.126; $p=0.012$ ), radiotherapy $(-/+)$ (HR 3.536; 95\% Cl 1.748-6. 854; $p=0.001)$, chemotherapy $(-/+)(\mathrm{HR} 3.733 ; 95 \% \mathrm{Cl} 1.994-$ $6.959 ; p<0.001$ ), and post-treatment pneumonia and other infections (HR 3.505; 95\% Cl 1.827-6.665; $p<0.001$ ); these were all determined to be independent prognostic factors (Table 2). 


\section{Discussion}

The increase in the number of elderly patients with malignant lymphoma is a common problem worldwide, but due to the high number of original and treatment-related complications[13], it is possible that they are not being treated satisfactorily. Zeremski et al[10]. retrospectively compared 20 consecutive cases in German Primary Central Nervous System Lymphoma Study Group-1(G-PCNSL-SG-1), which A comparative study was conducted between the HD-MTX basic therapy + whole-brain irradiation group as initial treatment and the irradiation avoidance group in which whole-brain irradiation was replaced with HD-AraC therapy, with 66 consecutive cases in the 'real-life group' treated otherwise. The median age was 62 and 70 years, with the real-life group being older, ECOG PS2-4 was $20 \%$ and $59.1 \%$, which also shows the poor condition of the real-life group, mOS was 33.4 months and 9.3 months, and mPFS was 24.8 months and 3.4 months, indicating that the elderly population was clearly in worse condition. Thus, there are very few studies of this population that are based on actual clinical practice, and in fact, there are probably quite a few cases that are not treated based on MRI diagnosis alone (BSC). In the present study, only 3 of 142 enrolled patients had BSC, and it was shown that EL-PCNSL was treated fairly aggressively. And also, our cases were treated much more aggressively than Zeremski et al.'s 'real-life group'[10] with a median age of 76 years and a PFS of $16 \mathrm{M}$ and OS of $24 \mathrm{M}$ despite much worse conditions than pretreatment KPS.

In addition, although some cases of PCNSL are difficult to image, Japanese patients usually have nongerminal center type DLBCL[14], and if PCNSL is immunocompetent, specific imaging findings such as CT, MRI, and FDG-PET, as well as clinical and spinal fluid examination findings, can be evaluated[15]. The risk of postoperative hemorrhage is also observed in a certain percentage of biopsy procedures[16]. In fact, in the present study, two cases of postoperative hemorrhage were observed, and one was a case of early death and dropout. Therefore, if possible, confirm by cerebrospinal fluid cytology before treatment, exclude secondary lymphoma by whole body $18 \mathrm{~F}$-fluorodeoxyglucose positron emission tomography (PET) [17], and enhancement dynamic susceptibility weighted magnetic resonance (DSC-MR) perfusion imaging is performed to exclude of high grade gliomas and metastatic brain tumors[18], and skipping the biopsy procedure and starting treatment might be one of the options for EL-PCNSL. The fact that there were $30 / 142(21.1 \%)$ such cases is useful information to be noted in the present study.

In the present study as well, treatment mainly by HD-MTX has been performed for the past 10 years, but it is estimated that treatment has been performed for each case according to the patient's condition, and the number of treatment cycles and radiation irradiation methods were mixed. Under such circumstances, on both univariate and multivariate analyses of the presence or absence of RT and the presence or absence of chemotherapy, the prognosis of patients treated with RT and chemotherapy was significantly different from that of those treated without. These results are noteworthy. The disadvantages of HD-MTXbased chemotherapy for EL-PCNSL are low rates of CR and PR and the short MPFS and mOS. A subanalysis of the elderly patients in the G-PCMD-SG-1 trial also showed that the CR+PR rate was $44 \%$, mPFS 4.0 was months, and mOS was 12.5 months, which was significantly worse than in the younger patients[13]. Furthermore, in the present study, the best response rate within 3 months $(C R+C R u)$ was 
65.4\%(87/133). Therefore, since Morris et al[19]. reported R-MPV therapy in 2013, R-MPV therapy has been introduced, but not all centers are on the same page, and the maximum follow-up period is 48 months, so the comparison with HD-MTX is short.

In our study groups, there are still few cases in which WBRT was avoided and chemotherapy alone was performed. Regarding the treatment of EL-PCNSL, leukoencephalopathy, which is a delayed neurotoxicity that occurs during radiation therapy and treatment process, cannot be ignored[20-22]. For this reason, clinical trials are now underway for all ages, omitting WBRT from initial induction therapy[23-25]. Similarly, in the EL-PCNSL, the ANOCEF-GOELAMS study[26] and PRIMAIN study[27], which avoid WBRT, have been conducted. In addition, oral tirabrutinib is now available in Japan[28], and prospective studies avoiding WBRT are expected in the future.

Elderly persons have a variety of physiological, organ, and motor functions that are impaired, and comorbidities before treatment are naturally more frequent. In addition, the timing and extent of the onset of physiological senile changes vary, making it difficult to determine treatment strategies for elderly patients. In the present study, many patients dropped out within 2 months, but it is also true that there are many cases of early acute death[29]. The IELSG score[30] and the MSKCC score[31] have been used as prognostic scores for malignant lymphoma. Of them, old age itself is considered a factor associated with a poor prognosis and is included in the score. However, in recent years, with the aging of the population, some argue that old age itself is not associated with a poor prognosis[1, 32].

There have been a couple of reports that pre-treatment low PS or KPS is associated with a poor prognosis in EL-PCNSL[33-37]. In the present cases, however, univariate analysis showed that pre-treatment KPS was irrelevant, but that rather there was a significant difference in KPS improvement after treatment. The reason for this might be that KPS would improve and the prognosis would improve if a therapeutic response were seen by aggressive intervention for EL-PCNSL patients. However, we believe that the cause of it not being identified as related to prognosis on Cox proportional hazards model is the strong factor of systemic pre-treatment comorbidities and after treatment complications. The significance of this suggestion that pre-treatment comorbidities, especially cardiac and central nervous system comorbidities, and post-treatment new infectious complications would influence prognosis is great, and this is a point of focus that has not received much attention in the past. In other words, if we pay attention to patients with pre-treatment comorbidities, minimize new post-treatment complications, and aggressively intervene in the treatment of patients with low PS, long-term survival would be expected even in EL-PCNSL patients.

\section{Declarations}

\section{Sources of funding}

This study did not receive any funding.

\section{Conflicts of interest}


The corresponding author has no conflicts to report.

\section{Availability of data and material}

The data that support the findings of this study are available on request from the corresponding author. The data are not publicly available due to privacy or ethical restrictions.

\section{Code availability}

None

\section{Author Contributions}

KA and $\mathrm{HO}$ contributed to the concept and design of the study.

$\mathrm{KA}$ and $\mathrm{MM}$ contributed to the acquisition and analysis of the data.

AK contributed to central pathological diagnosis.

All authors contributed to drafting the text and preparing the figure.

KA, YY, TO, MN, TB, KM, MI, and MK contributed to acquisition of the data in individual institutions.

KS,YS, KO, YF, HS, HO, and TT contributed to supervision in individual institutions.

YS, CK, TK, and TT contributed to supervision and advising on the whole project.

\section{Approval of the ethics committee}

This study was conducted with the approval of the ethics committees of Hirosaki University Graduate School of Medicine (2018-118) and individual institutions. In addition, since this study was a retrospective study, notifications to patients were opt-out to the homepage of each hospitals.

\section{Consent to participate}

The institutional review board waived the requirement for informed consent, owing to the retrospective nature of the study. However, the details of the study are posted on the hospital's homepage(http://www.med.hirosaki-u.ac.jp/ neuros/).

\section{Consent for publication}

We removed all identifiers from our records upon completion of our study to protect patients' privacy.

\section{Acknowledgments}

We would like to express our appreciation to all those who contributed to this study. Yuichi Sato MD, PhD (Department of Neurosurgery, Iwate Medical University), Masazumi Fujii MD, PhD (Department of 
Neurosurgery, Fukushima Medical University), Yoshihiro Kameoka MD, PhD, (Department of Hematology, Nephrology and Rheumatology, Akita University Graduate School of Medicine), all the doctors at all the institutions and the members of the Tohoku Brain Tumor Study Group, and all the stuffs of Department of Anatomic Pathology, Hirosaki University Graduate School of Medicine.

\section{References}

1. Daras M, DeAngelis LM (2013) Management of elderly patients with primary central nervous system lymphoma. Curr Neurol Neurosci Rep 13: 344 doi:10.1007/s11910-013-0344-5

2. Shibui S (2014) <BTRJ 13 54_sup.2014-0001.pdf>. Neurol Med Chir (Tokyo) 54: 10-102

3. Narita $Y$ (2017) <BTRJ 14 57_sup.2017-0001.pdf>. Neurol Med Chir (Tokyo) 57: 9-102

4. Villano JL, Koshy M, Shaikh H, Dolecek TA, McCarthy BJ (2011) Age, gender, and racial differences in incidence and survival in primary CNS lymphoma. $\mathrm{Br} \mathrm{J}$ Cancer 105: 1414-1418 doi:10.1038/bjc.2011.357

5. Mendez JS, Ostrom QT, Gittleman H, Kruchko C, DeAngelis LM, Barnholtz-Sloan JS, Grommes C (2018) The elderly left behind-changes in survival trends of primary central nervous system lymphoma over the past 4 decades. Neuro Oncol 20: 687-694 doi:10.1093/neuonc/nox187

6. Ostrom QT, Gittleman H, Xu J, Kromer C, Wolinsky Y, Kruchko C, Barnholtz-Sloan JS (2016) CBTRUS Statistical Report: Primary Brain and Other Central Nervous System Tumors Diagnosed in the United States in 2009-2013. Neuro Oncol 18: v1-v75 doi:10.1093/neuonc/now207

7. Ferreri AJ, Cwynarski K, Pulczynski E, Ponzoni M, Deckert M, Politi LS, Torri V, Fox CP, Rosée PL, Schorb E, Ambrosetti A, Roth A, Hemmaway C, Ferrari A, Linton KM, Rudà R, Binder M, Pukrop T, Balzarotti M, Fabbri A, Johnson P, Gørløv JS, Hess G, Panse J, Pisani F, Tucci A, Stilgenbauer S, Hertenstein B, Keller U, Krause SW, Levis A, Schmoll HJ, Cavalli F, Finke J, Reni M, Zucca E, Illerhaus G (2016) Chemoimmunotherapy with methotrexate, cytarabine, thiotepa, and rituximab (MATRix regimen) in patients with primary CNS lymphoma: results of the first randomisation of the International Extranodal Lymphoma Study Group-32 (IELSG32) phase 2 trial. Lancet Haematol 3 : e217-227 doi:10.1016/s2352-3026(16)00036-3

8. Schorb E, Finke J, Ferreri AJ, Ihorst G, Mikesch K, Kasenda B, Fritsch K, Fricker H, Burger E, Grishina O, Valk E, Zucca E, Illerhaus G (2016) High-dose chemotherapy and autologous stem cell transplant compared with conventional chemotherapy for consolidation in newly diagnosed primary CNS lymphoma--a randomized phase III trial (MATRix). BMC Cancer 16: 282 doi:10.1186/s12885-0162311-4

9. Fallah J, Qunaj L, Olszewski AJ (2016) Therapy and outcomes of primary central nervous system lymphoma in the United States: analysis of the National Cancer Database. Blood Adv 1: 112-121 doi:10.1182/bloodadvances.2016000927

10. Zeremski V, Koehler M, Fischer T, Schalk E (2016) Characteristics and outcome of patients with primary CNS lymphoma in a "real-life" setting compared to a clinical trial. Ann Hematol 95: 793-799 doi:10.1007/s00277-016-2602-5

Page $11 / 23$ 
11. Macdonald DR, Cascino TL, Schold SC, Jr., Cairncross JG (1990) Response criteria for phase II studies of supratentorial malignant glioma. J Clin Oncol 8: 1277-1280 doi:10.1200/jco.1990.8.7.1277

12. Abrey LE, Batchelor TT, Ferreri AJ, Gospodarowicz M, Pulczynski EJ, Zucca E, Smith JR, Korfel A, Soussain C, DeAngelis LM, Neuwelt EA, O'Neill BP, Thiel E, Shenkier T, Graus F, van den Bent M, Seymour JF, Poortmans P, Armitage JO, Cavalli F (2005) Report of an international workshop to standardize baseline evaluation and response criteria for primary CNS lymphoma. J Clin Oncol 23: 5034-5043 doi:10.1200/jco.2005.13.524

13. Roth P, Martus P, Kiewe P, Möhle R, Klasen H, Rauch M, Röth A, Kaun S, Thiel E, Korfel A, Weller M (2012) Outcome of elderly patients with primary CNS lymphoma in the G-PCNSL-SG-1 trial. Neurology 79: 890-896 doi:10.1212/WNL.0b013e318266fcb2

14. Shiozawa E, Yamochi-Onizuka T, Takimoto M, Ota H (2007) The GCB subtype of diffuse large B-cell lymphoma is less frequent in Asian countries. Leuk Res 31: 1579-1583 doi:10.1016/j.leukres.2007.03.017

15. Chiavazza C, Pellerino A, Ferrio F, Cistaro A, Soffietti R, Rudà R (2018) Primary CNS Lymphomas: Challenges in Diagnosis and Monitoring. Biomed Res Int 2018: 3606970 doi:10.1155/2018/3606970

16. Mizobuchi Y, Nakajima K, Fujihara T, Matsuzaki K, Mure H, Nagahiro S, Takagi Y (2019) The risk of hemorrhage in stereotactic biopsy for brain tumors. J Med Invest 66: 314-318 doi:10.2152/jmi.66.314

17. Mohile NA, Deangelis LM, Abrey LE (2008) The utility of body FDG PET in staging primary central nervous system lymphoma. Neuro Oncol 10: 223-228 doi:10.1215/15228517-2007-061

18. Goyal P, Kumar Y, Gupta N, Malhotra A, Gupta S, Gupta S, Mangla M, Mangla R (2017) Usefulness of enhancement-perfusion mismatch in differentiation of CNS lymphomas from other enhancing malignant tumors of the brain. Quant Imaging Med Surg 7: 511-519 doi:10.21037/qims.2017.09.03

19. Morris PG, Correa DD, Yahalom J, Raizer JJ, Schiff D, Grant B, Grimm S, Lai RK, Reiner AS, Panageas K, Karimi S, Curry R, Shah G, Abrey LE, DeAngelis LM, Omuro A (2013) Rituximab, methotrexate, procarbazine, and vincristine followed by consolidation reduced-dose whole-brain radiotherapy and cytarabine in newly diagnosed primary CNS lymphoma: final results and long-term outcome. J Clin Oncol 31: 3971-3979 doi:10.1200/jco.2013.50.4910

20. Schlegel U, Schmidt-Wolf IG, Deckert M (2000) Primary CNS lymphoma: clinical presentation, pathological classification, molecular pathogenesis and treatment. J Neurol Sci 181: 1-12 doi:10.1016/s0022-510x(00)00385-3

21. Wassenberg MW, Bromberg JE, Witkamp TD, Terhaard CH, Taphoorn MJ (2001) White matter lesions and encephalopathy in patients treated for primary central nervous system lymphoma. J Neurooncol 52: 73-80 doi:10.1023/a:1010676807228

22. Ferreri AJ, Abrey LE, Blay JY, Borisch B, Hochman J, Neuwelt EA, Yahalom J, Zucca E, Cavalli F, Armitage J, Batchelor T (2003) Summary statement on primary central nervous system lymphomas 
from the Eighth International Conference on Malignant Lymphoma, Lugano, Switzerland, June 12 to 15, 2002. J Clin Oncol 21: 2407-2414 doi:10.1200/jco.2003.01.135

23. Rubenstein JL, Hsi ED, Johnson JL, Jung SH, Nakashima MO, Grant B, Cheson BD, Kaplan LD (2013) Intensive chemotherapy and immunotherapy in patients with newly diagnosed primary CNS lymphoma: CALGB 50202 (Alliance 50202). J Clin Oncol 31: 3061-3068 doi:10.1200/jco.2012.46.9957

24. Pulczynski EJ, Kuittinen O, Erlanson M, Hagberg H, Fosså A, Eriksson M, Nordstrøm M, Østenstad B, Fluge $\varnothing$, Leppä S, Fiirgaard B, Bersvendsen H, Fagerli UM (2015) Successful change of treatment strategy in elderly patients with primary central nervous system lymphoma by de-escalating induction and introducing temozolomide maintenance: results from a phase II study by the Nordic Lymphoma Group. Haematologica 100: 534-540 doi:10.3324/haematol.2014.108472

25. Houillier C, Taillandier L, Dureau S, Lamy T, Laadhari M, Chinot O, Moluçon-Chabrot C, Soubeyran P, Gressin R, Choquet S, Damaj G, Thyss A, Abraham J, Delwail V, Gyan E, Sanhes L, Cornillon J, Garidi R, Delmer A, Tanguy ML, Al Jijakli A, Morel P, Bourquard P, Moles MP, Chauchet A, Gastinne T, Constans JM, Langer A, Martin A, Moisson P, Lacomblez L, Martin-Duverneuil N, Delgadillo D, Turbiez I, Feuvret L, Cassoux N, Touitou V, Ricard D, Hoang-Xuan K, Soussain C (2019) Radiotherapy or Autologous Stem-Cell Transplantation for Primary CNS Lymphoma in Patients 60 Years of Age and Younger: Results of the Intergroup ANOCEF-GOELAMS Randomized Phase II PRECIS Study. J Clin Oncol 37: 823-833 doi:10.1200/jco.18.00306

26. Omuro A, Chinot O, Taillandier L, Ghesquieres H, Soussain C, Delwail V, Lamy T, Gressin R, Choquet S, Soubeyran P, Huchet A, Benouaich-Amiel A, Lebouvier-Sadot S, Gyan E, Touitou V, Barrié M, del Rio MS, Gonzalez-Aguilar A, Houillier C, Delgadillo D, Lacomblez L, Tanguy ML, Hoang-Xuan K (2015) Methotrexate and temozolomide versus methotrexate, procarbazine, vincristine, and cytarabine for primary CNS lymphoma in an elderly population: an intergroup ANOCEF-GOELAMS randomised phase 2 trial. Lancet Haematol 2: e251-259 doi:10.1016/s2352-3026(15)00074-5

27. Fritsch K, Kasenda B, Schorb E, Hau P, Bloehdorn J, Möhle R, Löw S, Binder M, Atta J, Keller U, Wolf HH, Krause SW, Heß G, Naumann R, Sasse S, Hirt C, Lamprecht M, Martens U, Morgner A, Panse J, Frickhofen N, Röth A, Hader C, Deckert M, Fricker H, Ihorst G, Finke J, Illerhaus G (2017) High-dose methotrexate-based immuno-chemotherapy for elderly primary CNS lymphoma patients (PRIMAIN study). Leukemia 31: 846-852 doi:10.1038/leu.2016.334

28. Narita Y, Nagane M, Mishima K, Terui Y, Arakawa Y, Yonezawa H, Asai K, Fukuhara N, Sugiyama K, Shinojima N, Kitagawa J, Aoi A, Nishikawa R (2020) Phase 1/2 Study of Tirabrutinib, a SecondGeneration Bruton's Tyrosine Kinase Inhibitor, in Relapsed/Refractory Primary Central Nervous System Lymphoma. Neuro Oncol doi:10.1093/neuonc/noaa145

29. Ghesquières $H$, Drouet $Y$, Sunyach MP, Sebban $C$, Chassagne-Clement $C$, Jouanneau $E$, Honnorat $J$, Biron P, Blay JY (2013) Evidence of time-dependent prognostic factors predicting early death but not long-term outcome in primary CNS lymphoma: a study of 91 patients. Hematol Oncol 31: 57-64 doi:10.1002/hon.2021 
30. Ferreri AJ, Blay JY, Reni M, Pasini F, Spina M, Ambrosetti A, Calderoni A, Rossi A, Vavassori V, Conconi A, Devizzi L, Berger F, Ponzoni M, Borisch B, Tinguely M, Cerati M, Milani M, Orvieto E, Sanchez J, Chevreau C, Dell'Oro S, Zucca E, Cavalli F (2003) Prognostic scoring system for primary CNS Iymphomas: the International Extranodal Lymphoma Study Group experience. J Clin Oncol 21: 266272 doi:10.1200/jco.2003.09.139

31. Abrey LE, Ben-Porat L, Panageas KS, Yahalom J, Berkey B, Curran W, Schultz C, Leibel S, Nelson D, Mehta M, DeAngelis LM (2006) Primary central nervous system lymphoma: the Memorial SloanKettering Cancer Center prognostic model. J Clin Oncol 24: 5711-5715 doi:10.1200/jco.2006.08.2941

32. Siegal T, Bairey O (2019) Primary CNS Lymphoma in the Elderly: The Challenge. Acta Haematol 141: 138-145 doi:10.1159/000495284

33. Xie H, Dahiya S, Murphy ES, Chao ST, Suh JH, Stevens GH, Peereboom DM, Ahluwalia MS (2013) Primary central nervous system lymphoma in the elderly: the Cleveland clinic experience. Anticancer Res 33: 3251-3258

34. Kasenda B, Ferreri AJ, Marturano E, Forst D, Bromberg J, Ghesquieres H, Ferlay C, Blay JY, HoangXuan K, Pulczynski EJ, Fosså A, Okoshi Y, Chiba S, Fritsch K, Omuro A, O'Neill BP, Bairey O, Schandelmaier S, Gloy V, Bhatnagar N, Haug S, Rahner S, Batchelor TT, Illerhaus G, Briel M (2015) First-line treatment and outcome of elderly patients with primary central nervous system lymphoma (PCNSL)--a systematic review and individual patient data meta-analysis. Ann Oncol 26: 1305-1313 doi:10.1093/annonc/mdv076

35. Ney DE, Reiner AS, Panageas KS, Brown HS, DeAngelis LM, Abrey LE (2010) Characteristics and outcomes of elderly patients with primary central nervous system lymphoma: the Memorial SloanKettering Cancer Center experience. Cancer 116: 4605-4612 doi:10.1002/cncr.25363

36. Schuurmans M, Bromberg JE, Doorduijn J, Poortmans P, Taphoorn MJ, Seute T, Enting R, van Imhoff G, van Norden Y, van den Bent MJ (2010) Primary central nervous system lymphoma in the elderly: a multicentre retrospective analysis. Br J Haematol 151: 179-184 doi:10.1111/j.13652141.2010.08328.x

37. Lee SY, Okoshi Y, Kurita N, Seki M, Yokoyama Y, Maie K, Hasegawa Y, Chiba S (2014) Prognosis factors in Japanese elderly patients with primary central nervous system lymphoma treated with a nonradiation, intermediate-dose methotrexate-containing regimen. Oncol Res Treat 37: 378-383 doi:10.1159/000363435

\section{Tables}

Table 1. Clinical characteristics and results of univariate analysis 


\begin{tabular}{|c|c|c|c|}
\hline Characteristic & & $\begin{array}{l}\text { N (\%), Median (IQR), } \\
\text { Range, Median OS } \\
\text { (95\%CL) }\end{array}$ & $\begin{array}{l}p \text { value } \\
\text { (log-rank } \\
\text { test) }\end{array}$ \\
\hline \multirow[t]{3}{*}{ Age $(y)$} & Median & $76(73,80), 71-92$ & \multirow[t]{3}{*}{0.68} \\
\hline & $\geq 76$ & $24(12-30)$ & \\
\hline & $<76$ & $21(16-37)$ & \\
\hline \multirow[t]{2}{*}{ Sex } & Male & 65 (48.9) & \multirow[t]{2}{*}{0.09} \\
\hline & Female & $68(51.1)$ & \\
\hline \multirow[t]{3}{*}{ Time until diagnosis (month) } & Median & $1(1-2), 0.5-12$ & \multirow[t]{3}{*}{0.90} \\
\hline & $\geq 1$ & $26(16-32)$ & \\
\hline & $<1$ & $21(11-31)$ & \\
\hline \multirow[t]{3}{*}{ Pre-treatment KPS (\%) } & Median & $50(40,60), 30-90$ & \multirow[t]{3}{*}{0.54} \\
\hline & $\geq 50$ & $25(16-34)$ & \\
\hline & $<50$ & $21(12-31)$ & \\
\hline \multirow[t]{12}{*}{ Tumor location } & Frontal & $43(32.3)$ & \multirow[t]{12}{*}{-} \\
\hline & Temporal & $19(14.3)$ & \\
\hline & Parietal & $10(7.5)$ & \\
\hline & Occipital & $8(6.0)$ & \\
\hline & Cerebellum & $9(6.8)$ & \\
\hline & Corpus callosum & $13(9.8)$ & \\
\hline & Basal ganglia & $8(6.0)$ & \\
\hline & Thalamus & $9(6.8)$ & \\
\hline & Corona radiata & $5(3.8)$ & \\
\hline & Ventricle & $4(3.0)$ & \\
\hline & Hypothalamus & $3(2.3)$ & \\
\hline & Others & $2(1.5)$ & \\
\hline \multirow[t]{3}{*}{ Maximum tumor diameter (mm) } & median & $\begin{array}{l}36.3(25.6,46.7), 3.5- \\
75.3\end{array}$ & \multirow[t]{3}{*}{0.27} \\
\hline & $\geq 36.3$ & $24(15-41)$ & \\
\hline & $<36.3$ & $24(12-30)$ & \\
\hline Multicentric lesion & No & 66 (49.6), 25 (16-34) & 0.58 \\
\hline
\end{tabular}




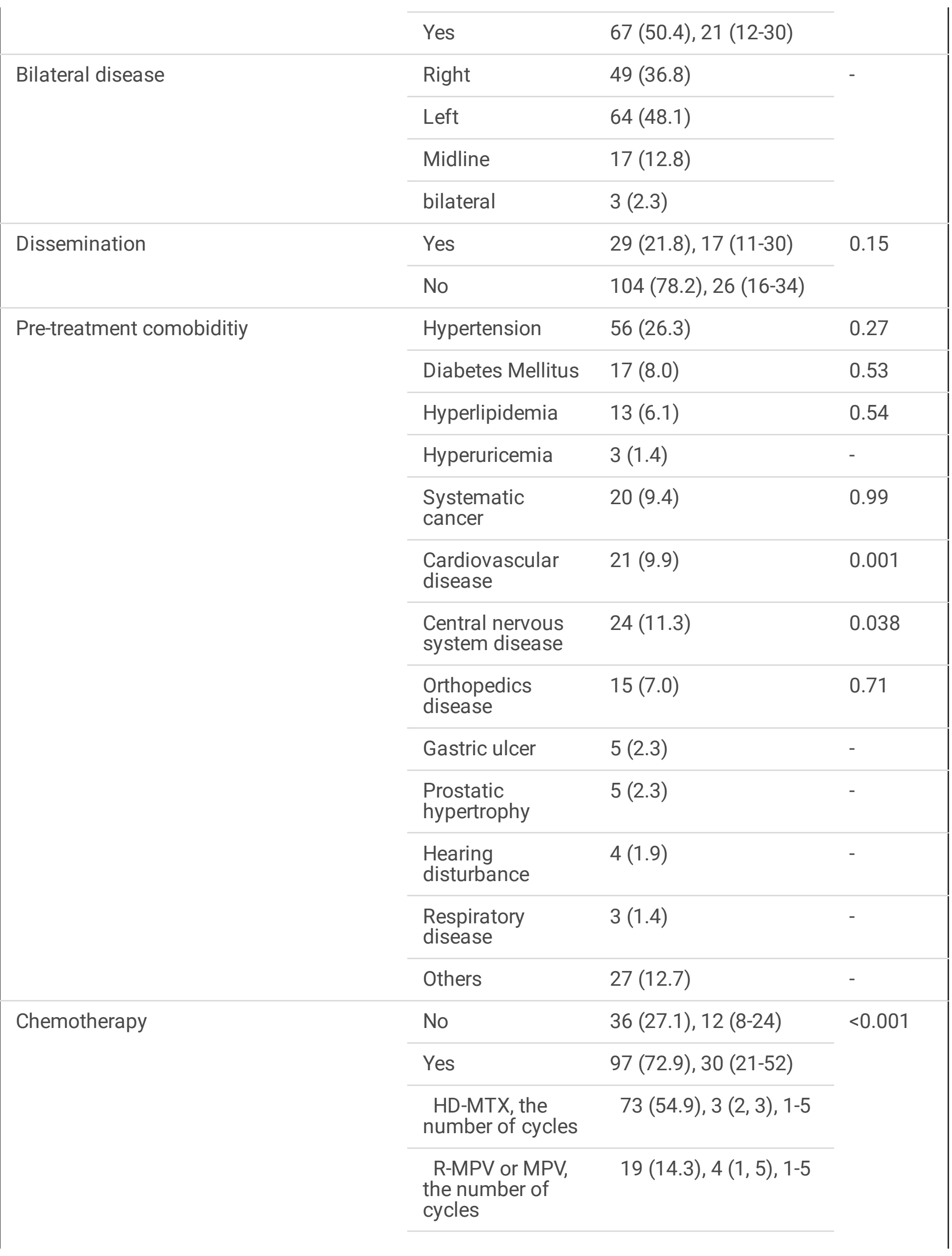




\begin{tabular}{|c|c|c|c|c|}
\hline & $\begin{array}{l}\text { CHOP etc, the } \\
\text { number of cycles }\end{array}$ & \multicolumn{2}{|c|}{$5(3.8), 3(3,5), 3-5$} & \\
\hline \multirow[t]{5}{*}{ Radiotherapy } & No & \multicolumn{2}{|c|}{23 (17.3), 9 (2-36) } & 0.045 \\
\hline & Yes & \multicolumn{2}{|c|}{110 (82.7), 25 (19-31) } & \\
\hline & LBRT & \multicolumn{2}{|c|}{$\begin{array}{l}11(8.3), 30(24 \\
40), 20-56\end{array}$} & \\
\hline & WBRT & \multicolumn{2}{|c|}{$\begin{array}{l}47(35.3), 30 \text { (23.4, } \\
30), 20-50.4\end{array}$} & \\
\hline & WBRT+LBRT & \multicolumn{2}{|c|}{$\begin{array}{l}52(39.0), 42(40 \\
50.3), 34-60\end{array}$} & \\
\hline \multirow[t]{7}{*}{ Pattern of treatment combination } & RT only & \multicolumn{2}{|c|}{$32(24.1)$} & - \\
\hline & HD-MTX+RT & \multicolumn{2}{|c|}{$59(44.4)$} & \\
\hline & $\begin{array}{l}\text { R-MVP(or MPV } \\
\text { or R-MPV-A)+RT }\end{array}$ & \multicolumn{2}{|c|}{$14(10.5)$} & \\
\hline & $\mathrm{CHOP}+\mathrm{RT}$ & \multicolumn{2}{|c|}{$5(3.8)$} & \\
\hline & HD-MTX & \multicolumn{2}{|c|}{$14(10.5)$} & \\
\hline & $\begin{array}{l}\text { R-MPV(or MPV } \\
\text { or R-MPV-A) }\end{array}$ & \multicolumn{2}{|l|}{$5(3.6)$} & \\
\hline & Nothing & \multicolumn{2}{|l|}{$4(3.0)$} & \\
\hline \multirow{6}{*}{$\begin{array}{l}\text { Best response assessment of CR and } \\
\text { CRu after treatment (operation) within } 3 \\
\text { months }\end{array}$} & $\mathrm{CR}$ & $\begin{array}{l}35 \\
(26.3)\end{array}$ & $\begin{array}{l}87(65.4), 30 \\
(19-35)\end{array}$ & 0.013 \\
\hline & $\mathrm{CRu}$ & \multicolumn{2}{|l|}{$\begin{array}{l}52 \\
(39.1)\end{array}$} & \\
\hline & PR & $\begin{array}{l}40 \\
(30.1)\end{array}$ & $\begin{array}{l}46(34.6), 12 \\
(6-24)\end{array}$ & \\
\hline & SD & \multicolumn{2}{|l|}{$\begin{array}{l}0 \\
(0.0)\end{array}$} & \\
\hline & PD & \multicolumn{2}{|l|}{$\begin{array}{l}3 \\
(2.3)\end{array}$} & \\
\hline & NE & \multicolumn{2}{|l|}{$\begin{array}{l}3 \\
(2.3)\end{array}$} & \\
\hline \multirow[t]{3}{*}{ Post-treatment KPS (\%) } & Median & \multicolumn{2}{|c|}{$60(40,75), 0-100$} & $<0.001$ \\
\hline & $\geq 60$ & \multicolumn{2}{|c|}{$34(21-52)$} & \\
\hline & $<60$ & \multicolumn{2}{|c|}{$12(8-21)$} & \\
\hline Post-treatment complications & $\begin{array}{l}\text { Pneumonia and } \\
\text { other infections }\end{array}$ & \multicolumn{2}{|c|}{$28(33.3)$} & $<0.001$ \\
\hline
\end{tabular}




\begin{tabular}{|c|c|c|c|}
\hline & $\begin{array}{l}\text { Gastro-intestinal } \\
\text { bleeding }\end{array}$ & $3(3.6)$ & - \\
\hline & DIC & $2(2.4)$ & - \\
\hline & $\begin{array}{l}\text { Cardiovascular } \\
\text { complications }\end{array}$ & $12(14.3)$ & 0.001 \\
\hline & $\begin{array}{l}\text { Symptomatic } \\
\text { epilepsy }\end{array}$ & $1(1.2)$ & - \\
\hline & $\begin{array}{l}\text { Postoperative } \\
\text { bleeding }\end{array}$ & $2(2.4)$ & - \\
\hline & $\begin{array}{l}\text { Renal function } \\
\text { damage }\end{array}$ & $11(13.1)$ & 0.41 \\
\hline & Others & $25(29.8)$ & - \\
\hline Second-line therapy & Subtotal & $61(100)$ & - \\
\hline & BSC & $32(52,5)$ & \\
\hline & Radiotherapy & $8(13.1)$ & \\
\hline & $\begin{array}{l}\text { Radiotherapy + } \\
\text { Chemotherapy }\end{array}$ & $8(13.1)$ & \\
\hline & Chemotherapy & $13(21.3)$ & \\
\hline Outcome & Alive & $39(29.3)$ & - \\
\hline & Dead & $76(57.1)$ & \\
\hline & $\begin{array}{l}\text { Impossible to } \\
\text { follow-up cases }\end{array}$ & $18(13.5)$ & \\
\hline
\end{tabular}

Values are or medians (interquartile range), ranges, or $\mathrm{n}(\%)$

KPS=Karnofsky Performance Status; HD-MTX=High dose methotrexate therapy; MPV=HD-

MTX+Procarbazine+Vincristine therapy; R-MPV= Rituximab+MPV therapy; R-MPV-A=R-MPV-AraC therapy; $\mathrm{CHOP}=$ Cyclophosphamide+Hydroxydaunorubicin+Vincristine+Prednisolone therapy; LBRT=Local boost radiation therapy; $\mathrm{WBRT}=$ Whole brain radiation therapy; $\mathrm{CR}=$ Complete response; $\mathrm{CRu}=\mathrm{CR} /$ unconfirmed; $\mathrm{PR}=$ Partial response; $\mathrm{SD}=$ Stable disease; $\mathrm{PD}=$ Progressive disease; $\mathrm{NE}=$ Not evaluable; $\mathrm{DIC}=$ Disseminated intravascular coagulation; $\mathrm{BSC}=$ Best supportive care

Table 2. Cox proportional hazard model of factors associated with overall survival 


\begin{tabular}{|c|c|c|c|}
\hline Characteristic & $p$ value & Hazard ratio & $95 \% \mathrm{Cl}$ \\
\hline Age $(\geq 76 /<76 y)$ & 0.06 & 1.739 & $0.994-3.046$ \\
\hline $\operatorname{Sex}(M / F)$ & 0.20 & 1.434 & $0.824-2.488$ \\
\hline Pre-treatment KPS $(<50 / \geq 50 \%)$ & 0.33 & 1.337 & $0.749-2.436$ \\
\hline \multicolumn{4}{|l|}{ Pre-treatment comobiditiy } \\
\hline $\mathrm{HT}(+/-)$ & 0.93 & 1.030 & $0.507-2.008$ \\
\hline DM (+/-) & 0.43 & 0.701 & $0.276-1.688$ \\
\hline $\mathrm{HL}(+/-)$ & 0.72 & 1.212 & $0.393-3.270$ \\
\hline Systemic cancer (+/-) & 0.44 & 0.753 & $0.349-1.507$ \\
\hline Cardiovascular disease (+/-) & 0.002 & 3.432 & $1.612-7.065$ \\
\hline Central nervous system disease (+/-) & 0.012 & 2.869 & $1.280-6.126$ \\
\hline Chemotherapy $(-/+)$ & $<0.001$ & 3.733 & $1.994-6.959$ \\
\hline Radiotherapy $(-/+)$ & 0.001 & 3.536 & $1.748-6.854$ \\
\hline Post-treatment RR (CR+CRu) & 0.08 & 1.677 & $0.949-2.923$ \\
\hline Post-treatment KPS (60>/ $\geq 60 \%)$ & 0.32 & 1.352 & $0.749-2.439$ \\
\hline \multicolumn{4}{|l|}{ Post-treatment complications } \\
\hline Pneumonia and other infections (+/-) & $<0.001$ & 3.505 & $1.827-6.665$ \\
\hline Cardiovascular complications (+/-) & 0.43 & 1.380 & $0.609-2.948$ \\
\hline Renal dysfunction (+/-) & 0.08 & 3.091 & $0.884-9.123$ \\
\hline
\end{tabular}

KPS=Karnofsky Performance Status; $\mathrm{HT}=$ Hypertension; $\mathrm{DM}=$ diabetes mellitus; $\mathrm{HL}=$ Hyperlipidemia; $\mathrm{RR}=$ Response rate; $\mathrm{CR}=$ Complete response; $\mathrm{CRu}=\mathrm{CR} /$ unconfirmed; $\mathrm{DVT}=$ Deep venous thrombosis; $\mathrm{PE}=$ Pulmonary embolism

\section{Figures}




\section{Registration ( $\mathrm{N}=142)$}

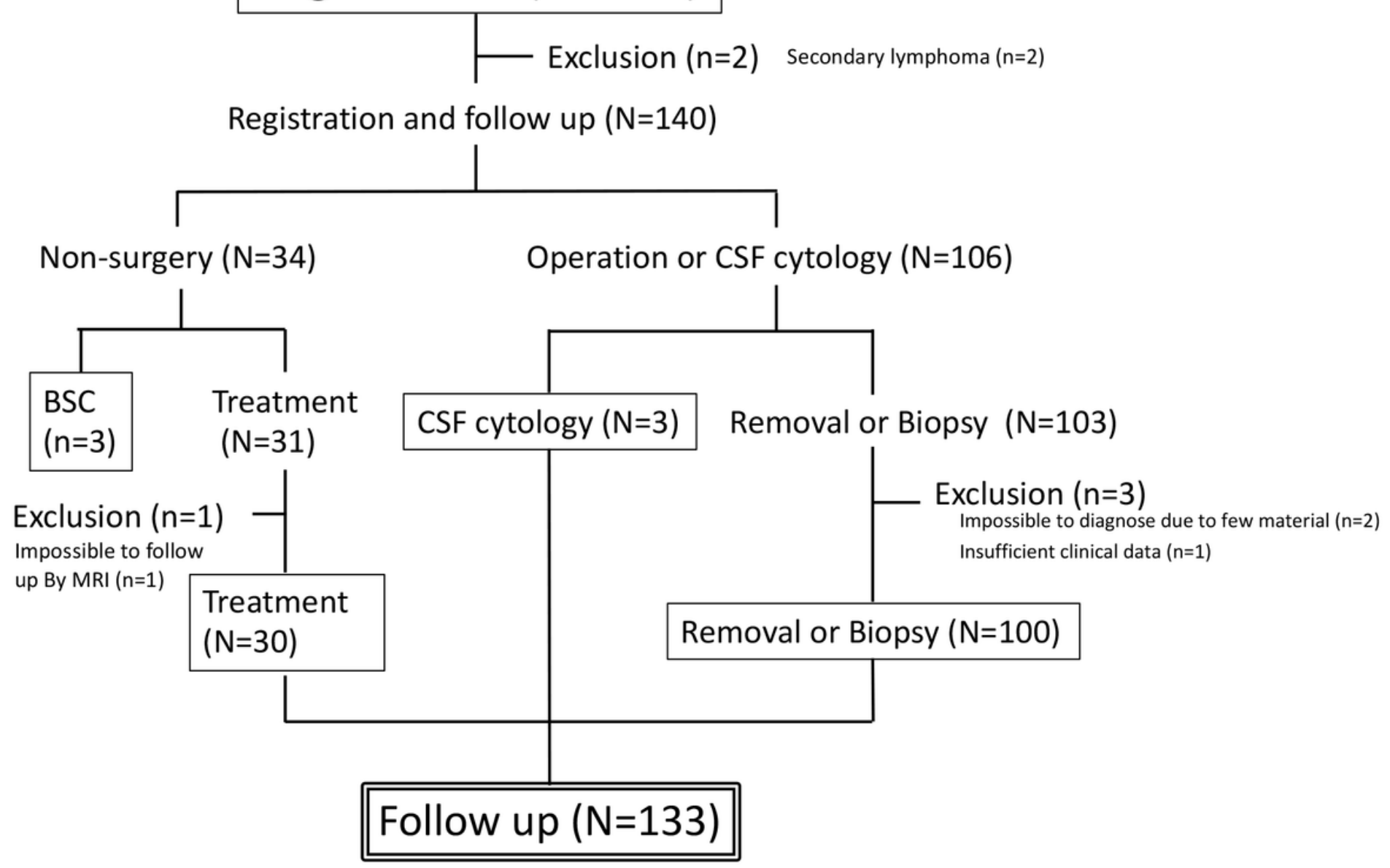

Fig. 1

\section{Figure 1}

CONSORT-style flow diagram of the study. The study involved 133 of 142 consecutive elderly patients with primary central nervous system malignant lymphoma in three groups. The first group was 3 patients in the best supportive care group of treatment without biopsy. The second group included 30 patients in the treatment group without biopsy. The third group included 3 patients in the cerebrospinal fluid cytology group and 100 patients in the biopsy and central pathological confirmation group. 

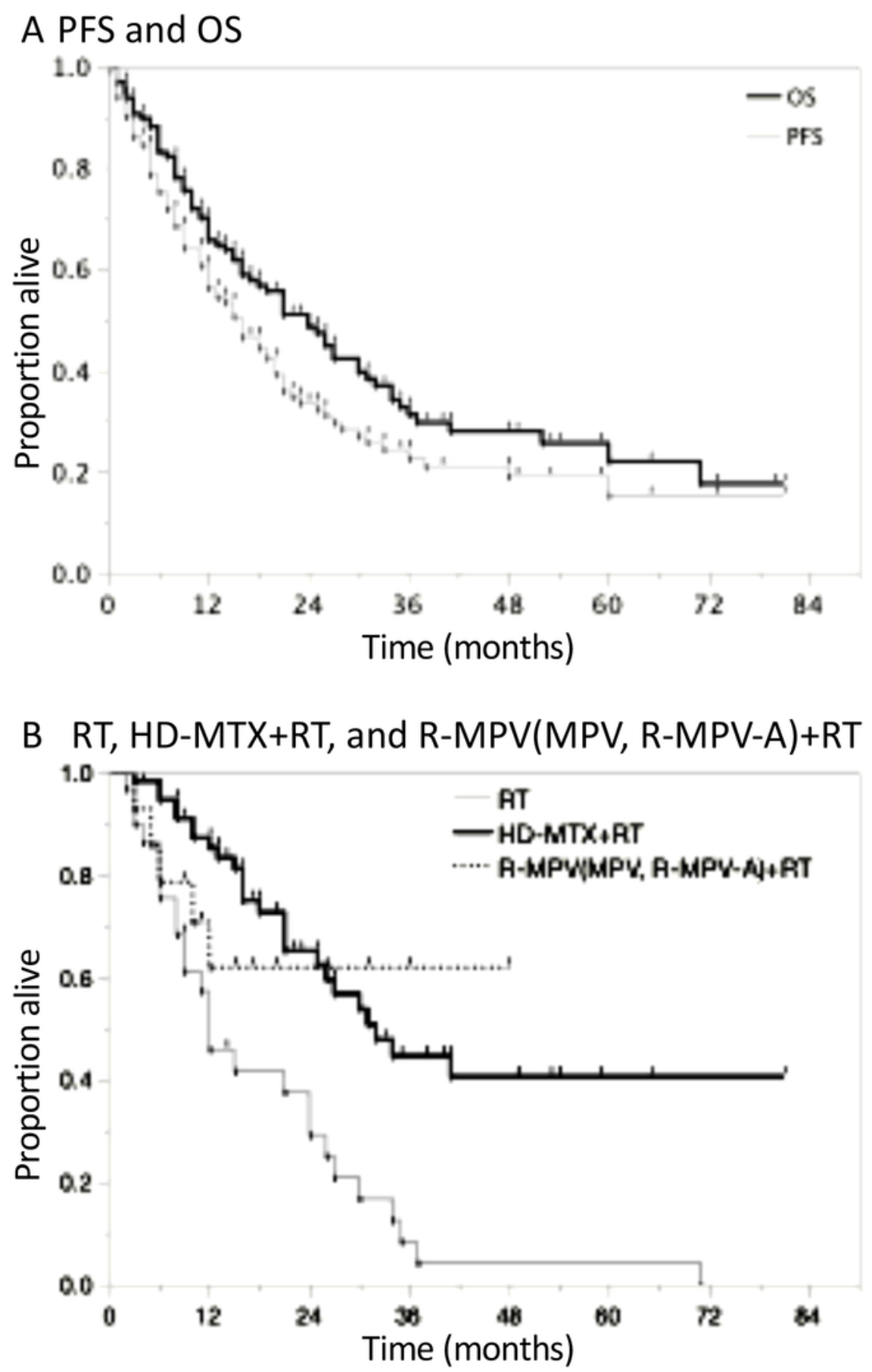

Fig. 2

Figure 2

CONSORT-style flow diagram of the study. The study involved 133 of 142 consecutive elderly patients with primary central nervous system malignant lymphoma in three groups. The first group was 3 patients in the best supportive care group of treatment without biopsy. The second group included 30 patients in the treatment group without biopsy. The third group included 3 patients in the cerebrospinal fluid cytology group and 100 patients in the biopsy and central pathological confirmation group. 

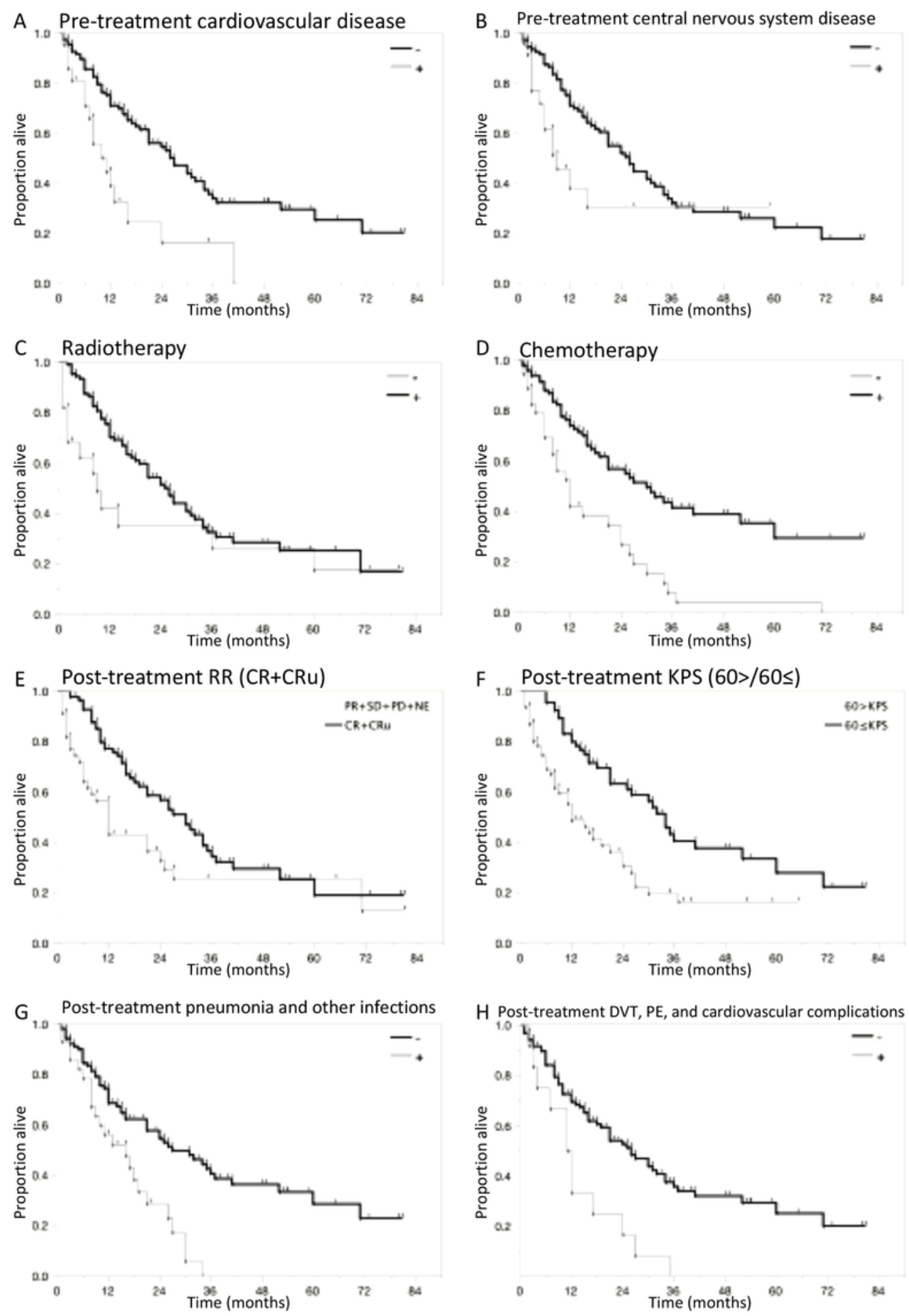

Fig. 3

\section{Figure 3}

Kaplan-Meier survival curves of independent variables. A: OS in patients with pre-operative cardiovascular disease (gray line) and without pre-operative cardiovascular disease (black line) $(p=0.001)$. B: OS in patients with pre-operative central nervous disease (gray line) and without pre-operative central nervous disease (black line) $(p=0.038)$. C: OS in patients who received radiotherapy (black line) and who did not receive radiotherapy (gray line) $(p=0.045)$. D: OS in patients who received chemotherapy (black line) and 
who did not receive chemotherapy (gray line) $(\mathrm{p}<0.001)$. E: OS in patients who achieved best response assessment of $\mathrm{CR}$ and $\mathrm{CRu}$ (black line) and who did not achieve best response assessment of $\mathrm{CR}$ and Cru (gray line) $(p=0.013)$. F: OS in patients with a post-treatment KPS score $\geq 60$ (black line) and $<60$ (gray line) $(p<0.001)$. G: OS in patients with post-treatment pneumonia or other infections (gray line) and without post-treatment pneumonia and other infections (black line) $(\mathrm{p}<0.001)$. H: OS in patients with posttreatment deep venous thrombosis (DVT), pulmonary embolism (PE), or cardiovascular complications (gray line) and without post-treatment DVT, PE, and cardiovascular complications (black line) $(p=0.001)$. 